\title{
PEDESTRIAN BEHAVIOR FOR DEVELOPING STRATEGY IN TOURISM AREA; AGENT-BASED SIMULATION
}

\author{
Nova Asriana \\ Department of Architecture, University Langlangbuana, Jalan Karapitan No.116, Bandung \\ Email: novaasriana@gmail.com
}

\begin{abstract}
Agent-based modelling is an approach to develop a design strategy in socio-related studies to understand pedestrian behavior by using simulation through validation using field observation. One of the likely case study is Palembang, South Sumatra which has historic city that having several potential advantages in destination tourists and also having urban issues. Some facilities disseminate prosperous for domestic tourist destination, transportation hubs (land and water-based transport), and public facilities. The purpose is to develop design strategy of pedestrian behavior in urban space to be procedure based on computational modelling. By merging the result, it helps designers to depict pedestrian movement flow, permeability and connectivity patterns, which represent the presumptions of the origins or source of movement, destinations, generators and attractors of movement in tourism area. This simulation examines and evaluates spatial behavior models allowing to route preferences each pedestrian in order to be used in strategy of design process for architect, urban planner or other designer stakeholders. In addition, the potential pattern of movement, connectivity, density and accessibility will predict a spatial structure of pedestrian regarding the strategy design and planning then also it will be benefit for a suitable zoning which refers a walkable pedestrian-way design as an approach of a pedestrian behavior and experience.
\end{abstract}

Keywords: Pedestrian; agent-based modelling; design strategy, tourism.

\section{INTRODUCTION}

Previous work by researchers has established that most of the pedestrian simulations are conducted for pedestrian flows and evacuation scenarios in crowded infrastructures and simulate pedestrian movement in an urban outdoor environment, especially for planning purposes (Knura, 2019). Agentbased simulation for the pedestrian is implemented and focused especially on simulating the impact density and diversity in prime criteria for decision process occupants (Aschwanden, 2012). It studies particularly on reactive agents and starts from a detailed analysis of their interaction (Klügl \& Bazzan, 2012). This investigation can reveal a network of people flow by using a simulation model that is applied to the design of spatial circulation within building and urban areas (Sharma \& Tabak, 2008), also it is suitable in socio-related studies, especially urban studies (Bonabeau, 2002) and advocated as a breakthrough in computational modelling in social sciences (Gilbert \& Terna, 2000). Simulating users' behavior in a built environment is important for predicting and evaluating urban and building performance before the buildings are built which can evaluate the environments' effect on human behavior (Yan \& Kalay, 2006). The implementation of agents' simulation identifies justification of predictions and assumptions in both building scale and city-scale for varied purposes in the design strategy process (Asriana \& Indraprastha, 2016).
Agent-based simulation approached human movement has a purposive movement result in models that exemplify explicitly the origins and destinations or the attractors and generators of movement. These assumptions in rational choice or agents' route decision are either predefined as travel time (Penn \& Turner, 2001) and pattern movement can facilitate people to move in an urban environment and also indicate how pedestrians are able to adjust the street environment and usable space (Beavon et al., 1994). In addition, it can determine pedestrian walkability in the neighborhoods (Leslie et al., 2007). However, if the movement activities on pedestrian experience are not addressed and distributed effectively in design, particularly lack of pedestrian concern, it would show a decisive miss match on balanced land use planning to develop sustainable walkability (AlMamun, Begum, \& Mowla, 2018).

According to these researchers to date has tended to concern for social science in an indoor or urban outdoor environment for planning and design study, such as station, airport, and pedestrian flows in crowded infrastructures by using agent-based modelling. The tool predominately revolves around a specific area or city on a small scale where the pedestrian is moving and leaving during casual mundanity by standard scenario tools, as for example, pedestrians start and finish their movement in a vivid route. Therefore, this paper is to address the empirical evidence which links daily pedestrian behavior in standard-setting (waypoint condition), tourists' behavior 
(wayfinding condition), and modelling simulation that is formulated by the pseudocode in grasshopper. The agents are not the only pedestrian who have known the area, but also tourists who are unfamiliar and distracted by other agents or the surrounding environment which is a lack of signage. Also, this paper tries to examine the waypoint and wayfinding scenario which occurs in a tourism complex that has various facilities, such as a transportation hub (land and waterbased transport), plaza, and public facilities in a historic and commercial district. This constructive modelling simulation aims to help decision-makers and urban designers in the strategy of the decisionmaking process for developing a plan in the tourism area.

\section{LITERATURE REVIEW AND METHODOLOGY}

General and practical in the design process, the purpose of facility program or spatial needs based on holistic thinking approach and sometimes inadequate walkability concern in pedestrian circulation flow in design development. Applying agent-based simulation is an experimental based to give experience for pedestrian circulation and movement flow, peculiarly in a tourism area. It will depict potential measurability and precision in design decision making and this potency also gives a significant aspect of prediction in movement that illustrates the patterns of movement of person or groups in a scene over space and time, whereby a person's current position is based on its first position, desired destination and surrounding, including the physical environment and other people (Batty, 2003) where this modelling is growing for urban design in recent years (Chen, 2012). Even pedestrians often engage in unconscious decisions that difficult to explain or measure, which means might not be translated easily (Ronald et al., 2007). Nevertheless, in spite of the ubiquity of pedestrian movement, understanding how pedestrians move in and explore the space around them persists in an underlying scientific challenge (Crooks et al., 2015). Therefore, this investigation applies this computational modelling simulation, agent-based, as a tool to help designers speculate for design developing strategy in the tourism area. Then, the result simulation is an important output of this modelling that describes the numbers of people traveling along various routes, and the algorithms that are used are frequently based on observation modelling algorithms (Ronald et al., 2007). This study has considered three stages, they are (1) identify boundary site, which refers to the physical environment and sort of activities, (2) setting agent variables, which refer to agent sources as the main source of movement and some controllers to influence of pedestrian movement, also how pedestrian choose their route to fulfill their destination agenda, and (3) agent-based simulation, which refers to simulation process, which will describe the actual process of walking and pedestrian behavior reaction to avoid collisions with obstacles or other pedestrians.

\section{IDENTIFY BOUNDARY SITE}

The scope area of the study case is located historically known for waterfront tourism area and part of urban nodes of Musi Riverside, Palembang, and South Sumatra. The area is framed by the Musi River on the southern part and surrounded by a heritage district on the northern part. Moreover, this area has a breathtaking spatial experience, such as in the middle of the commercial district of Palembang, the capital city, circled by historical and traditional kampong and the most noticeable feature is that this spot now is favorable for domestic tourist destinations and transportation hub (Figure 1a).

In this paper, to identify boundary site as physical experience is using the image of city elements, namely path, district, node, edge, and landmark (Lynch, 1960), where people usually use landmark as a benchmark in their movement. The trajectories of the benchmark will generate further route decisions as spatial significance in the urban environment. The path is to create a well-circulated area and good quality of space which convinces and guides pedestrians' final destination route. Meanwhile, node, district, and edge show the pedestrian activities as generator and attractor sources to tempt or distract the pedestrian. This case study presents the physical environment features (Figure 1b) to know the influence aspects to the pedestrian.

According to this observation site, the case area was classified into four zoning activities (Zone A, B, $\mathrm{C}, \mathrm{D})$ by daily arrival visitors and also by influenced activities on physical features. The activities are observed based on periodic time (morning-afternoonnight), not only during weekdays but also during the weekend. Given is an observation comparing the activities by four different zones, namely Zone A segmented a fortress of BKB (Benteng Kuto Besak), a dock for riverboats, Ampera Bridge (Figure 2). Zone B illustrates Ampera Convention Center and historical artifacts, such as Monpera Museum, SMB Museum, and a dock for riverboat (Figure 3). Zone C describes an amazing view of Ampera Bridge and Musi River, under Ampera Bridge, shelter for public transport (Bus Rapid Transportation and Light Rail Transit), parking space, public space, and stairs to Ampera Bridge (Figure 4). The last, Zone D illustrates green area and socio-public space (Figure 5). 

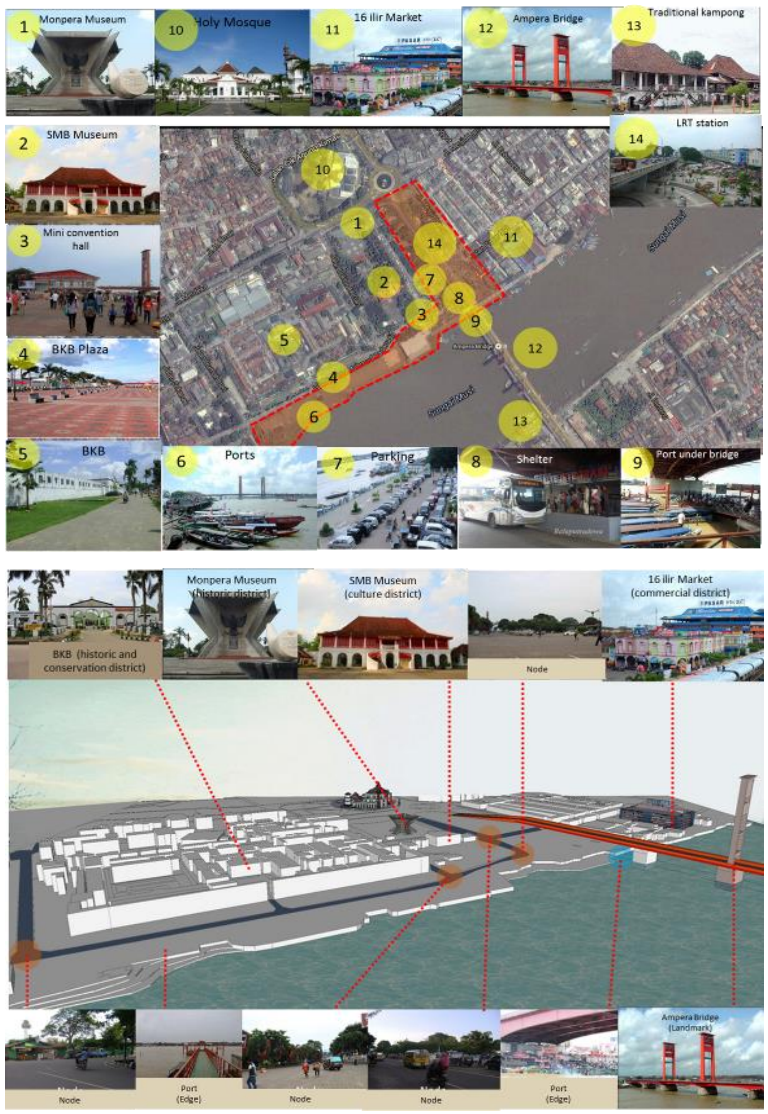

Fig. 1. (a) boundary site and (b) city elements

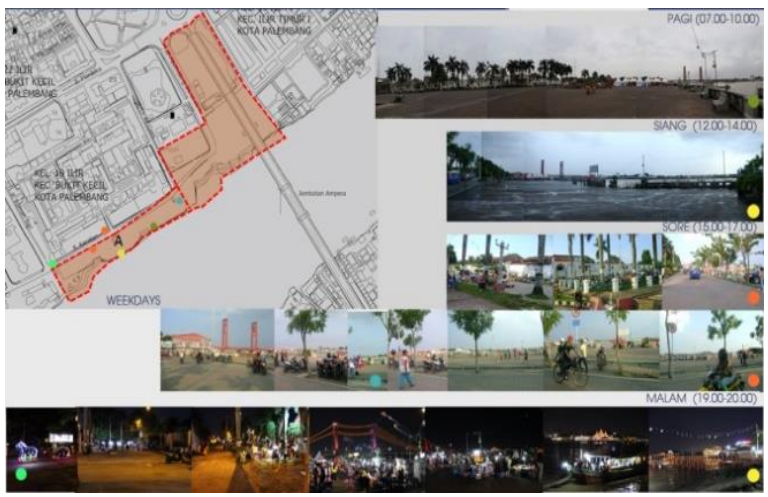

Fig. 2. Daily activities in Zone A

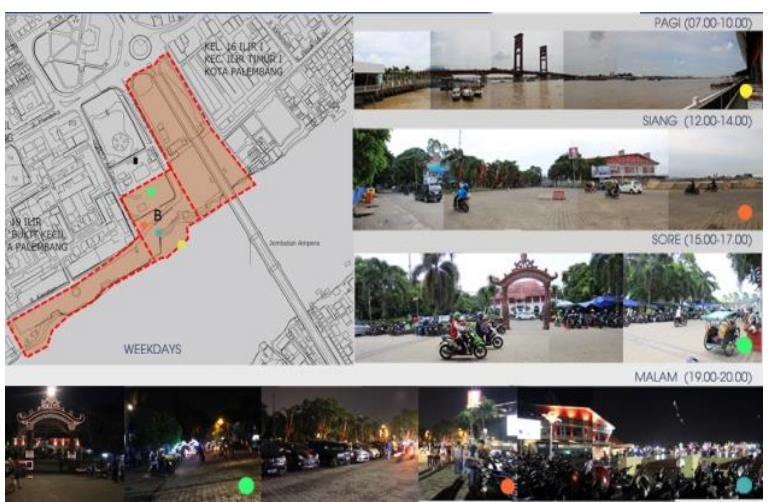

Fig. 3. Daily activities in Zone B

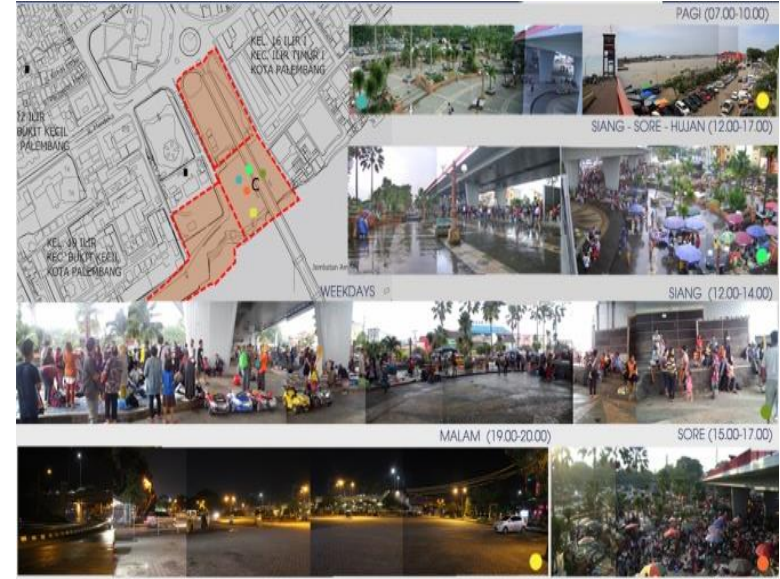

Fig. 4. Daily activities in Zone C

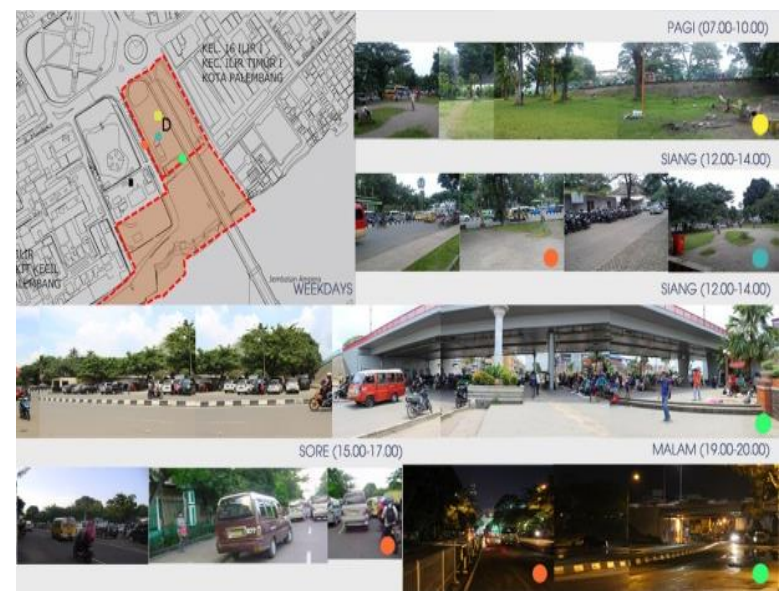

Fig. 5. Daily activities in Zone D

These observation sites determine non-physical parameters for pedestrians, such as main attractors, sources of movement, repulsive physical forces, and repulsive environmental forces (Figure 6). Main attractors are categorized as attractors to attract pedestrians in passing through these points which include heritage buildings, Musi River, Musi Riverside, promenade, commercial district, Ampera Bridge (as a landmark), and special events along Musi River. In addition, Figure 1.6 depicts the sources of movement that come from the arrival of public transportation (LRT Station and BRT Shelter) and parking areas. Meanwhile, repulsive physical forces are categorized as obstacle avoidance which is avoided by visitors and pedestrians to pass through this area, because sometimes there are criminal points, traffic congestion, parking space, insufficient signage, and loading dock hustle. Repulsive environmental forces are categorized as obstacle avoidance in the environment, such as the inconvenience of streetscapes, inappropriate smell, and irregular vegetation patterns. 

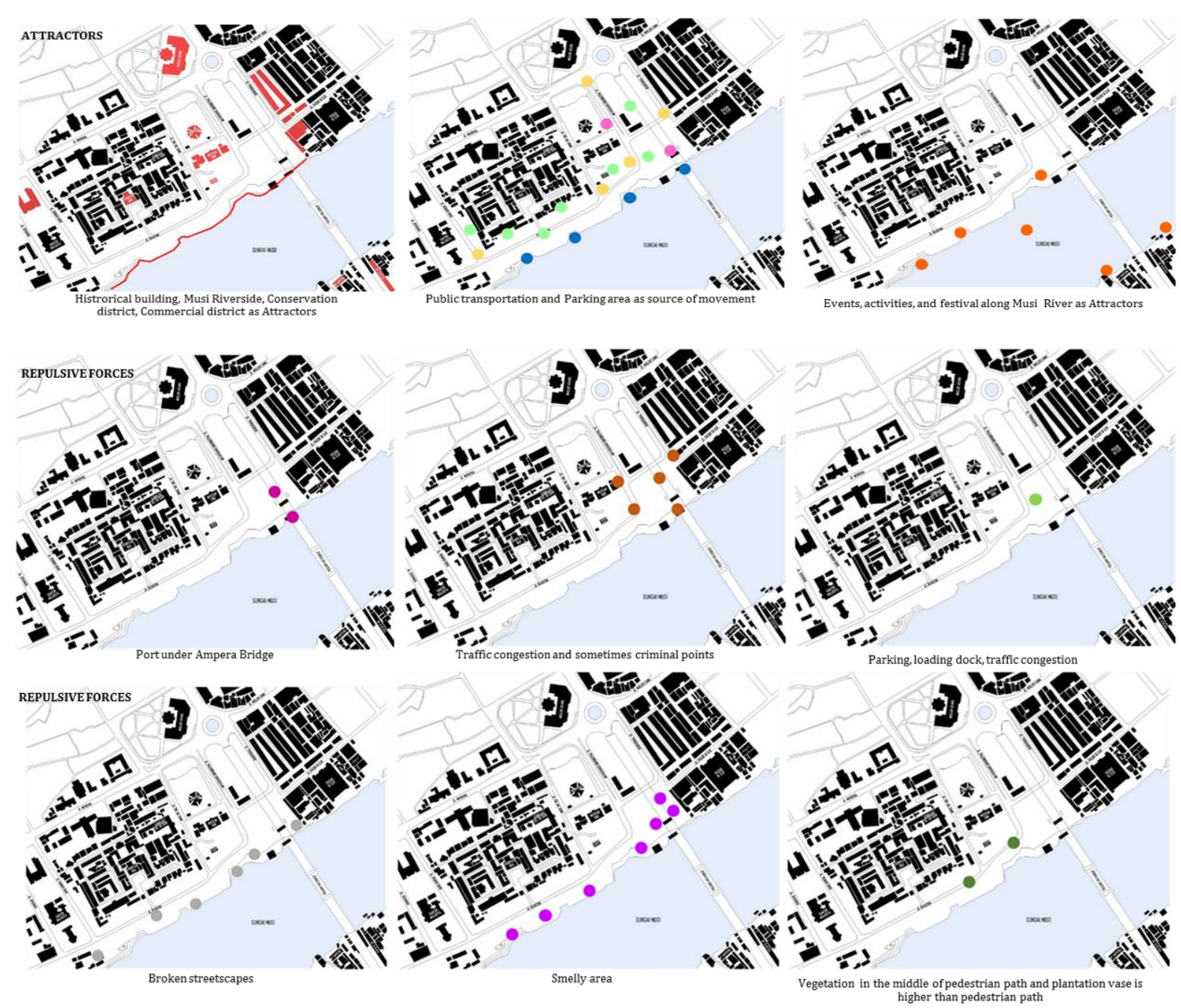

Fig. 6 Categorization of non-physical parameters, such as attractors, repulsive forces, and source of agents

\section{SETTING AGENT VARIABLES}

Correspondingly, before starting the simulation, the author remaps some variables based on observation. There is some classification of agent setting variables that will be data input for simulation, such as agent sources, agents' number of steps, agents' speed, agents' reaction to forces, agents' force, agents' length, and agents' engine speed (Table 1). Agent sources or "gateways" are locations in the city where people become active pedestrians and core features of urban simulation (Batty, 2005) (Haklay et al., 2001) because this simulation tool depends on the existence of this spot of simulation area. In this case study, agent sources are categorized into three sources, such as agents arrive from land and water-based transportation, parking space, shelter public transport (BRT and LRT), an agent from traffic congestion. Subsequently, agent setting variables will apply to the tool plugin of grasshopper, namely the agent-based plugin that is developed by Alex J. Fischer, and then these variables will be translated and set up into some tools in this plugin. These tools purpose to simulate pedes- trian flow based on agents' behavior in field observation before processing the simulation. Therefore, the simulation result

Table 1. Agents' setting variables

Agents' setting variables

Pedestrian sources Points

(Agents' sources) - Agents's sources transferring from land and wáter-based transportation, and viceversa. It is assumed around 40 agents each of arrival transferring

- Agents arrival point from parking space and shelter is assumed around 40 agents

- Agents arrival point from congestion points is assumed 40 agents

Lifespan (L) Number of time steps

Mass (M) Affecting how strongly the agent reacts to forces

Max Speed (S) Agents move incrementally by this speed towards targets that it seeks (Max index $=1$ )

Max Force (F) Steering ability can be controlled by limiting the magnitude of the steering forces (Max index $=1$ )

History Length (N) The number of past position to remember for each agent, normally length $=50$

Engine speed (V) Engines run the simulation 


\section{AGENTS' MOVEMENT CONTROL}

Agents' movement control is behavior reactions from some forces to influence movement agents. It will steer agents to traverse from one point to other points and find their final destinations. Usually, pedestrian move and find to final destinations, but if these destinations cannot be seen by the pedestrian, means the pass-through destination as a temporary goal (Alexander, Ishikawa, \& Silverstein, 1977). Furthermore, the pedestrian will have a temporary and final destination in their movement. In the term of this simulation, detailed pedestrian movements are controlled by behavior reaction, not only the interaction agent to the physical urban environment (extrinsic behavior) but also the interaction agent to agent or agent to groups (intrinsic behavior). In rule-based models, the focus is set on pedestrian intrinsic behavior, implementing decision-making based on predefined rules (Knura, 2019). There are five kinds of interactions of agents, such as goal-seeking, obstacle avoidance, separation, cohesion, and alignment (Table 2) (Indraprastha \& Shinozaki, 2009).

Table 2. Agents' control behavior

\begin{tabular}{ll}
\hline Control agents to groups \\
\hline Goal seeking & $\begin{array}{l}\text { Behavior in steering to find destination } \\
\text { points }\end{array}$ \\
Obstacle/Avoidance & $\begin{array}{l}\text { Behavior in steering to avoid static obstac- } \\
\text { les/avoidance } \\
\text { Behavior in steering forces to describe per- } \\
\text { Sonal zone }\end{array}$ \\
Cohesion & $\begin{array}{l}\text { Behavior in steering forces to group } \\
\text { Behavior in steering forces to align with } \\
\text { Alignment }\end{array}$ \\
\hline
\end{tabular}

Table 3. Agents' type and agents' environment behavior

\begin{tabular}{ll}
\hline Agents' type & \\
Waypoint agents & $\begin{array}{l}\text { Agents' behaviour in steering forces based on } \\
\text { goal getter (lack of distraction). This case } \\
\text { study, the waypoint agents are local people }\end{array}$ \\
Wayfinding agents & $\begin{array}{l}\text { Agents' behaviour in steering based on route } \\
\text { choices to explore more around destinations } \\
\text { (usually affected by attraction and full of } \\
\text { distraction). This case study, the wayfinding } \\
\text { agents are tourist }\end{array}$ \\
\hline Control agents to environment \\
\hline View & $\begin{array}{l}\text { Forces to move the agent away from any } \\
\text { agent that blocks its view }\end{array}$ \\
Attractor & $\begin{array}{l}\text { Forces to attract agent within the radius of } \\
\text { points }\end{array}$ \\
Followpath & $\begin{array}{l}\text { Force to an agent to move along and stay } \\
\text { within a specified radius of a curve or edges }\end{array}$ \\
Surface & $\begin{array}{l}\text { Surface environment upon wich the agents } \\
\text { environment }\end{array}$ \\
Contain & $\begin{array}{l}\text { Applies forces to keep agents away from } \\
\text { environment boundaries }\end{array}$ \\
\hline (Source: data derived from Grasshopper: add on plugin Agent)
\end{tabular}

According to Alan J. Fischer, this process simulation needs to add some parameters for agents' environment behavior for completing the simulation formula (Table 3). The additional parametes is to evaluate pedestrian modelling in a built environment through spatial adaptively by classified types of agents. It consists of three parameters; urban features, type of pedestrians (wayfinding pedestrian and waypoint pedestrian) (Kontovourkis, 2011).

\section{AGENT-BASED SIMULATION}

Pedestrian as actors in urban systems that focus on spatial cognition for routing and orientation aims as a research approach (Filomena \& Verstegen, 2018). Before starting the process of simulation, the author illustrates firstly the basic flow mapping scenarios of pedestrian movement trajectories genuinely based on observation as consideration and comparison as simple data input. Based on this flow, this diagram representation is known how the pedestrian circulates in the movement of the urban area (Fig. 7).

After mapping and generating pedestrian movement trajectories and routing network pedestrian, this research demonstrates a computer-based design approach that is used for generating circulation diagrams of functional areas at macro-scale level (Kontovourkis, 2011) and examine the applicable scope as one of the basic assumptions in existing spatial behavior models; the route preferences each pedestrian's level (Kitazawa \& Batty, 2004). Basically, it is influenced by defining and identifying attractor points, movement agents' sources, repulsive sources, and movement generators.

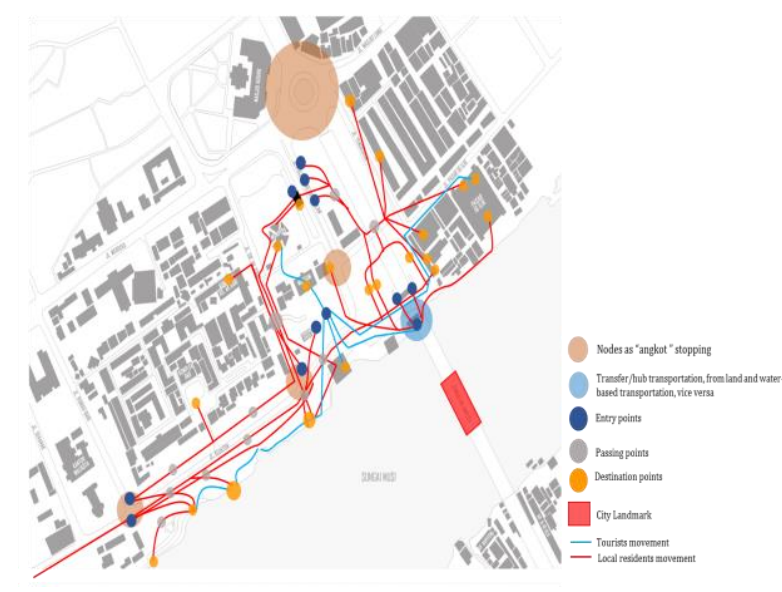

Fig. 7. Generating the routing network of pedestrian based on observation 


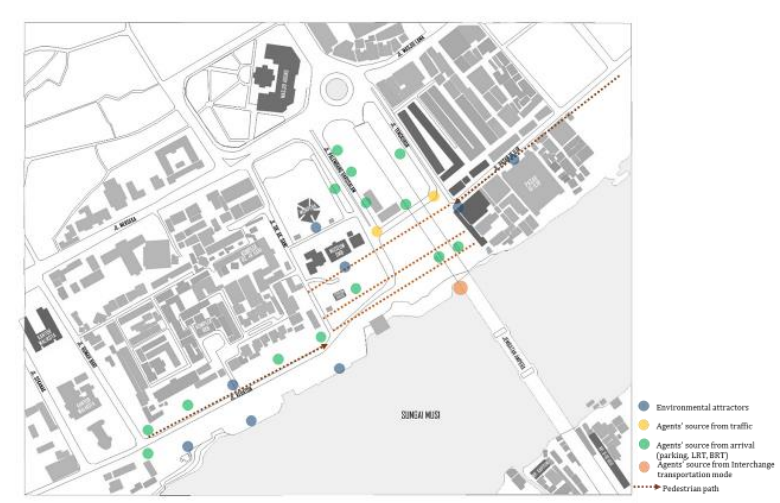

(a)

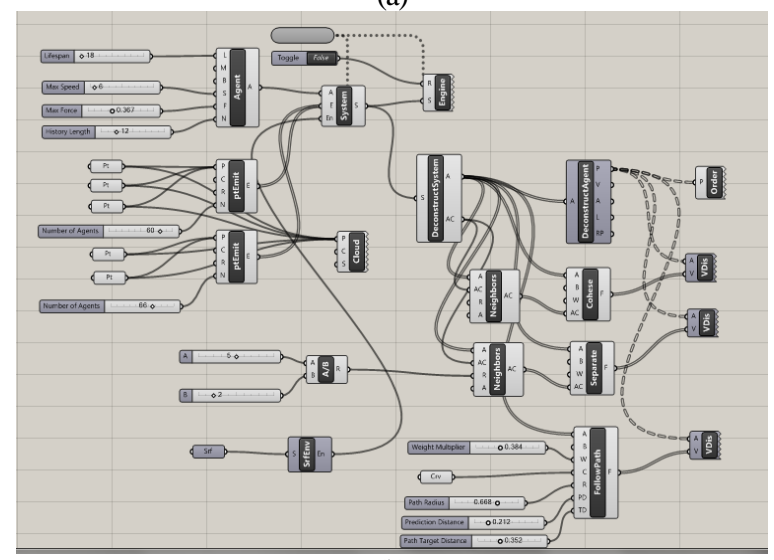

(b)

Fig. 8. (a) Generating type agents' sources and environment attractors, (b) pseudocode pedestrian movement -agent based simulation (Source: (a) personal documentation and (b) pseudocode formulated manually in Grasshopper software)

\section{RESULTS AND DISCUSSION}

In agent-based modelling, pedestrians or agents are defined as systems that can sense their environment and act on it in pursuit of their own destination. Also, this simulation is enhanced by simple behavior rules presented in Figure 9 in order to generate more realistic pedestrian movement patterns. These rules are modified by real pedestrian movement data and information about the physical or non-physical environment through observation. So that, this simulation classifies operational simulation into two developed scenarios simulation (Figure 9); (a) agents based pedestrians react and respond to the activity surrounding them, for instance, site boundaries, the physical environment, and other agents, (b) agents are steered by following a given set of scenarios as a destination agenda, for example, some locations to reach, a certain flocking agent wants or attracts to walk with, and a wayfinding heuristic rule to the next destination.
Based on this simulation, these studies and these scenarios indicate that waypoint and wayfinding pedestrian then author can conclude that most of pedestrian trail is influenced by several various attractors which describe density level of pedestrian movement in this area, especially in tourism area. Given all that has been simulated scene so far, pedestrian is attracted not only in physical environment attractors, but also in agents' interaction between agent to agent and agents to group. On the other hand, pedestrian avoid obstacles not only in physical environment, but also in agents' interaction between agent to agent and agents to group. These factors is usually related to daily route and way point condition of local pedestrian movement, where the local pedestrian have a familiarity this area than tourists. Meanwhile, some pedestrian is attracted by spatial use, such commercial district, heritage district, Public Park, riverside and promenade which has a breathtaking view, activities along river and experience in spatial environment. This indicates a link between unpredictable route and spatial use that is influenced by unimagined event or condition. This condition identifies way finding condition of tourists who are unfamiliarity and strangeness in this area. More heterogeneous spatial use in this area, it will be found or looked for by wayfinding pedestrian. Moreover, the simulation shows the number of movement intersections that depict the level connectivity and in relation the intensity of land use which has a fundamental effect to distribute of urban activities. This description of distributed urban activities draw spatial structure of pedestrian. Then the result of pedestrian movement trails will help designers or other stakeholders to take decision making in strategy of design process regarding the planning, design and management pedestrian area. It will determine classification which a suitable zoning which concern a walkable pedestrian-way design in the site as well as next an effective tool design strategy to develop designing and planning for tourism area.

Overlaid image (Figure 10) depicts accessible path and non-accessible path for pedestrian trails. These patterns might indicate some node activities which might be identifiable types of neighborhood, center and core activities, attractor activities and network path to further design. Pedestrian behavior's show people how they interact each other or environment by this simulation. 

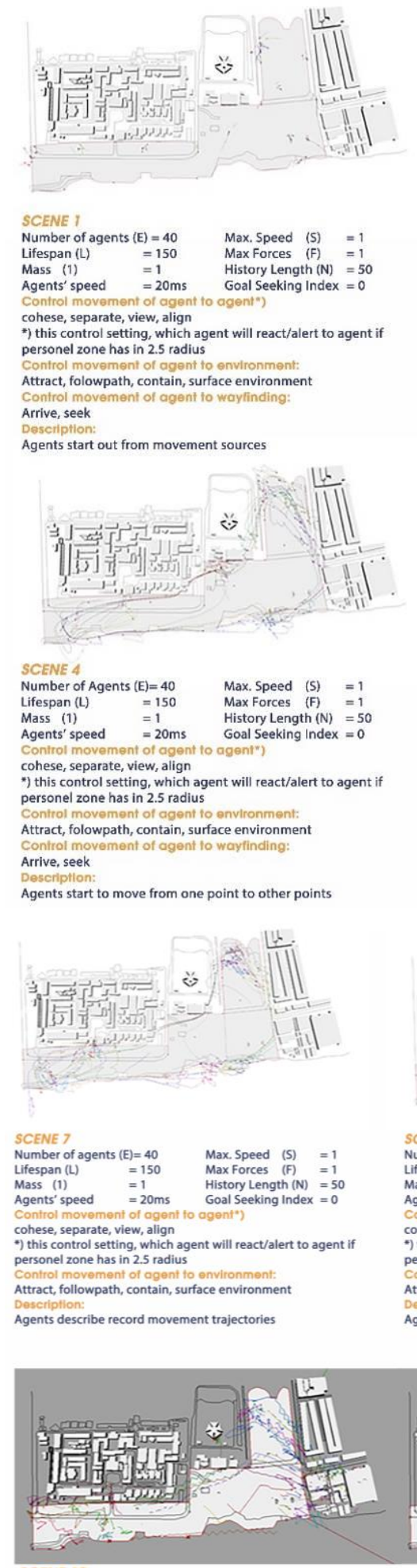

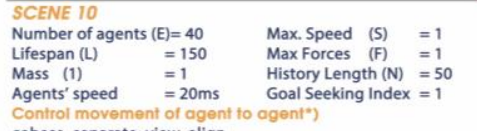

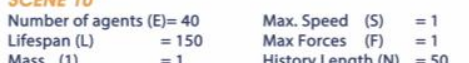

cohese, separate, view, align

") this control setting, which agent will react/alert to agent if personal zone has in 2.5 radius

Atract followpth, contain, suffacentronment:

Description:

When goal seeking variable has index $>0$, agents will find and look for attractors around environment, which is set up in the simulation. In this case study, agents are more interested in various
facilities (shopping area and Museum; Pasar 16 ilir-Museum SMB)

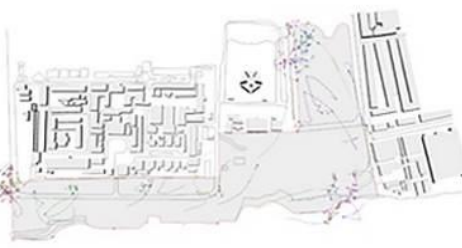

SCENE 2

Number of Agents $(E)=40 \quad$ Max. Speed $(S) \quad=1$ $\begin{array}{lll} & =150 \quad \text { Max Forces (F) }=1 \\ \text { Mass (1) } & =1 & \text { History }\end{array}$ Agents' speed $\quad=20 \mathrm{~ms} \quad$ Goal Seeking Index $=0$ Control movement of agent to agent") cohese, separate, view, align
") this control setting, which agent will react/alert to agent if personel zone has in 2.5 radius

Control movement of agent to environment: Attract, folowpath, contain, surface environmer Arrive, seek

Agents start out from movement sources toward several attractors

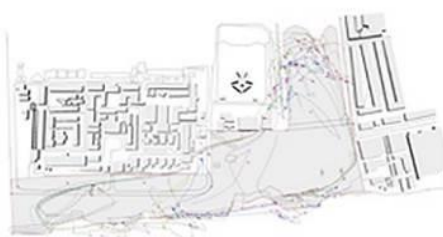

SCENE 5

Number of Agents $(E)=40 \quad$ Max. Speed (S) $=1$ $\begin{array}{lll}\text { Lifespan (L) } & =150 \quad \text { Max Forces }(F)=1 \\ \text { Mass (1) } & =1 & \text { History Lenth }\end{array}$ Agents' speed $\quad=20 \mathrm{~ms} \quad$ Goal Seeking Index $=0$ Control movement of agent to agent*) cohese, separate, view, align
*) this control setting, which agent will react/alert to agent if personel zone has in 2.5 radius Atrir movoment of agent to environment: Controt movern, contan, sunface environment Arrive, seek

Arrive, seek

Agents describe record movement trajectories

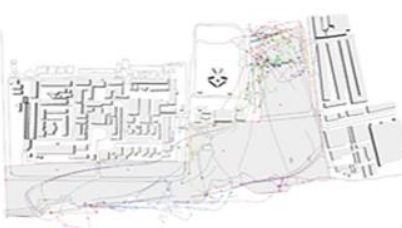

SCENE 8

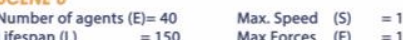
$\begin{array}{llll} & =150 & & \text { Max Forces } \\ \text { Mass (1) } & =1 & \text { History Length }(\mathrm{N}) & =1 \\ & =50\end{array}$ $\begin{aligned} \text { Agents speed } & =20 \mathrm{~ms} \quad \text { Gistory Length }(\mathrm{N})=50 \\ \text { Coal Seeking Index } & =0\end{aligned}$ cohese, separate, view, align ") this control setting, which agent will react/alert to agent if personel zone has in 2.5 radius Attract, followpath, contain, surface environment

Agents describe record movement trajectories
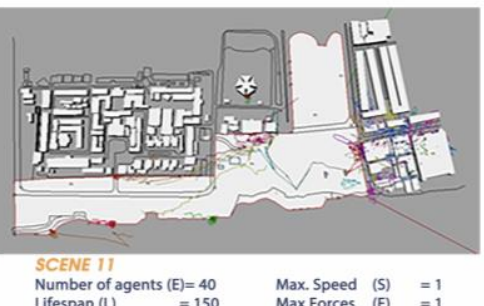
$\begin{array}{rlrl}\text { Lifespan (L) } & =150 \quad \text { Max Forces }(F)=1 \\ \text { Mass (1) } & =1 & \text { History Length }(N)=50\end{array}$ $\begin{array}{ll}\text { Agents' speed } & =20 \mathrm{~ms} \quad \text { Goal Seeking Index }=1 \\ \text { Control movement of agent to agent") } & \end{array}$ Control movente ef agont to agenty)

*) this control setting, ahich Desct, followpath, contain, surface environment

When goal seeking variable has index $>0$, agents will find and simulation. In this case study, agents are more interested in various facilities (shopping area and Museum; Pasar 16 ilir-

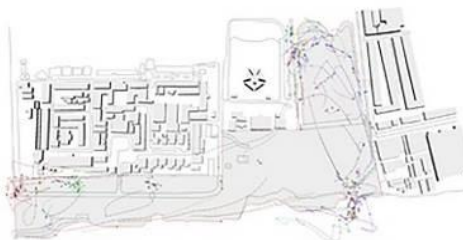

SCENE 3

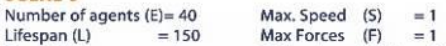
$\begin{array}{llll}\text { Lifespan (L) } & =150 & \text { Max Forces }(F)=1 \\ \text { Mass (1) } & =1 & \text { History Length }(\mathrm{N})=50\end{array}$ Agents' speed $\quad=20 \mathrm{~ms} \quad$ Goal Seeking Index $=0$ cohese, separate, view, align *) this control setting, which agent will react/alert to agent if personel zone has in 2.5 radius Control movement of agent to environment: Attract, folowpath, contain, surface environment Arrive, seek Arrive, seek

Agents start out from movement sources and then agents have huge explosions

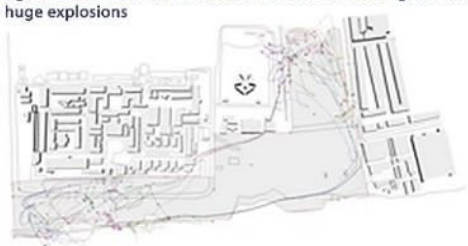

SCENE 6

$\begin{aligned} \text { Number of agents }(E)=40 \quad \text { Max. Speed } & (\mathrm{S}) \quad=1 \\ =150 \quad \text { Max } & =1\end{aligned}$ $\begin{array}{llll}\text { Lifespan (L) } & =150 & \text { Max Forces }(F)=1 \\ \text { Mass (1) } & =1 & \text { History Length (N) }=50\end{array}$ Agents' speed $=20 \mathrm{~ms}$ Goal Seeking Index $=0$ Control movement of agent to agent"? cohese, separate, view, align
*) this control setting, which agent will react/alert to agent if personel zone has in 2.5 radius

Attract folowpath, contain surface environt: Attract, folowpath, contain, surface environment Arrive, seek

Agents describe record movement trajectories

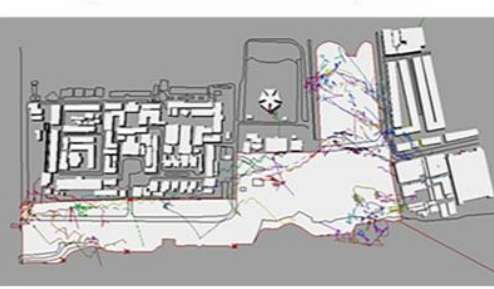

\section{SCENE 9}

$\begin{aligned} \text { Number of agents }(E)=40 \quad \text { Max. Speed }(S) & =1 \\ =150 \quad \text { Max Forces } & (F)=1\end{aligned}$ Mass (1) $\quad=1 \quad$ History Length $(\mathrm{N})=50$ Agents' speed $=20 \mathrm{~ms} \quad$ Goal Seeking Index $=1$ cohese, separate, view, allin to ogont ')

") thise, separate, view, align in 2.5 radius Attract, followpath, contain, surface environment

When goal seeking variable has index $>0$, agents will find and look for attractors around environment, which is set up in the simulation. In this case 16 ilir)

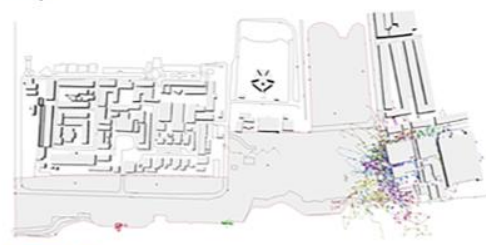

SCENE 12

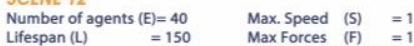

$\begin{array}{llll}\text { Lifespan (L) } & =150 & \text { Max Forces }(F)=1 \\ \text { Mass (1) } & =1 & \text { History Length } & =1 \\ & =1(N) & =50\end{array}$

$\begin{aligned} \text { Agents' speed } & =20 \mathrm{~ms} & \text { Goal Seeking Index } & =1\end{aligned}$

Control movement of agent to agent"?

cohese, separate, view, align

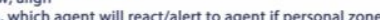
has in 2.5 radius

Control movement of agent to environment:

Final result, most pedestrian (local, tourist) try to find the most attractive Descripilon most pedestran (local, tourist) ty to find

Fig. 9. Generating the routing network of pedestrian based on agent-based scenarios simulation (Source: Grasshopper software result) 


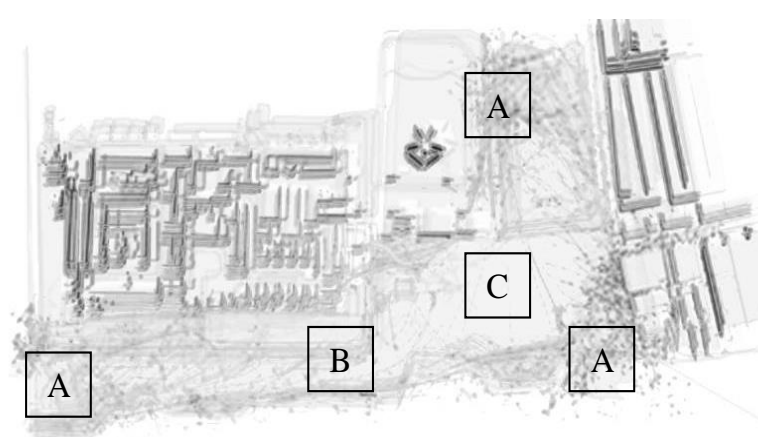

Fig. 10. Overlaid pedestrian trails

Experimenting and using agent-based simulation in predesign process is mainly as tools for designer to represent pedestrian movement trails in urban area and also to evaluate the design strategy. The pedestrian patterns in the existing tourism site reveal density, connectivity, and accessibility movement level by considering site boundaries and urban features. According to the experimental simulation, there are several types of density, connectivity, accessibility of pedestrian movement in the area (A, $\mathrm{B}$, and $\mathrm{C}$ in Table 4). The last simulation results (Scene 1-11 in Figure 9) are the closest similar result to the pattern by field observation, while scene 12 in Figure 9 is the result for most wayfinding pedestrian who are unfamiliar with the area and lack of direction. Most pedestrian are tourists who are distracted and attracted by group activities and heterogeneous spatial use in environment so that it will be useful to set up some additional facilities precisely in the area that will be relevant in pedestrian-way design. Then using this result further will be a basis for design guidelines, especially to categorize some node activities patterns before facilities building or environmental development are built in this tourism area.

Table 4. Pattern categories

\begin{tabular}{ll}
\hline \multicolumn{1}{c}{ Categories } & Explanation \\
\hline A High Density & This spatial refers to be used in high \\
& movement and a suitable to set spatial \\
& program which has high temporary \\
& mobility, such as interchange transport \\
& (e.g form and to land and public water- \\
& based transport) \\
& This spatial refers to be used in average \\
& movement or passing area and suitable \\
& to set zoning tourism to facilitate agents' \\
& explosión form Zone A (e.g promenade, \\
Average Density & corridor) \\
& This spatial refers to be used in private \\
& facilities or flexible function and a \\
& suitable to set spatial tourism program \\
& which needs comfortable and less noisy \\
& (e.g gallery, park, tourist information \\
C Low Density & center, green space, or temporal events) \\
\hline
\end{tabular}

\section{CONCLUSION}

Considering all the mentioned findings above, experimenting in agent-based simulation for pedestrian behavior as a developing strategy in the tourism area offers well-known advantages, despite several limitations. This simulation can play a role in possible pedestrian-centric design to strengthen the experience of character area, especially for tourism complex and it will help the designer in predesign process, evaluate spatial behavior based on route preferences of each pedestrian, or reevaluate proposal design before building the development facilities. For example, the simulation of route pedestrian in wayfinding mode is influenced by physical environment attractors and agents' interaction as their preferences and orientation to find buildings or potential activities in a tourism area. Therefore, a designer should concern pedestrian preferences, paths, trajectories, and orientation, when this area will be extended for a tourism complex to forefend disorientation and improve pedestrian understanding of how changes in this area. In addition, this simulation presents the further challenges and possibilities to deepen understanding on how the connectivity index will be regarding a walkable pedestrianway design, not only for experience in urban environment but also for mitigation in urban resilience, especially for unique location that might has geographical condition, urban issues, and potential activities development.

\section{ACKNOWLEDGMENT}

I would like to thank my supervisors in the process of this research Dr. Firmansyah and Aswin Indraprastha, Ph.D. to get my master's in Architecture, School of Architecture, Planning, and Policy Development Institut Teknologi Bandung.

\section{REFERENCES}

Alexander, C., Ishikawa, S., \& Silverstein, M. (1977). A Pattern Language; Towns, Building, Construction. Oxford University Press.

Al-Mamun, M. M., Begum, A. A., \& Mowla, Q. A. (2018, June). Walkability for Urban Sustainability: Study of Pedestrian Traffic in Chittagong. Jahangirnagar University Plannind Review, 16, 87-102.

Aschwanden, G. D. P. A. (2012). Agent-Based Social Pedestrian Simulation for the Validation of Urban Planning Recommendations. SIGraDi 2012Proceedings of the 16th Iberoamerican Congress of Digital Graphics - Brasil - Fortaleza 13-16 November 2012. 
Asriana , N., \& Indraprastha, A. (2016). Making Sense of Agent-Based Simulation; Developing Design Strategy fo Pedestrian-Centric Urban Space. The 21st International Conference of the Association for Computer-Aided Architectural Design Research in Asia CAADRIA, 343-352. Melbourne, Australia.

Batty, M. (2003). Agent-Based Pedestrian Modelling (Centre for Advanced Spatial Analysis).

Batty, M. (2005). Cities and Complexity.

Beavon, D. J. K., Brantingham, P. L., \& Brantingham, P. J. (1994). The influence of street networks on the patterning of property offenses. Crime Prevention Studies, 2(2), 115-148. http://www.popcenter.org/library/crimepreventio n/volume_02/06beavon.pdf

Bonabeau, E. (2002). Agent-based Modeling; Methods and Techniques for Simulating Human Systems. Proceeding of The National Academy of Science, 99(3), 7280-7287.

Chen, L. (2012). Agent-based modeling in urban and architectural research: A brief literature review. Frontiers of Architectural Research, 1(2), 166177. https://doi.org/10.1016/j.foar.2012.03.003

Crooks, A., Croitoru, A., Lu, X., Wise, S., Irvine, J. M., \& Stefanidis, A. (2015). Walk This Way: Improving Pedestrian Agent-Based Models Through Activity Analysis. ISPRS International Journal of Geo-Information, 1627-1656. https://doi.org/10.3390/ijgi4031627

Filomena, G., \& Verstegen, J. (2018). Mental Representation of Space in Agent Based Models for Pedestrian Movement in Urban Environment: A Conceptual Model. Geospatial Technologies for All: Short Papers, Posters and Posters Abstract of the 21th AGILE Conference on Geographic Information Science.

Gilbert, N., \& Terna, P. (2000). How to Build and Use Agent-Based Models in Social Science. Mind and Society, 1(1), 57-72.

Indraprastha, A., \& Shinozaki, M. (2009). New Framework of Behavioral-Based Simulation for Spatial Design Assessment. Proceeding of The 11th International Conference on Computers in Urban Planning and Urban Management (CUPUM). Hongkong: University of Hongkong.

Kitazawa, K., \& Batty, M. (2004). Pedestrian Behaviour Modelling; An Application to Retail Movements using a Genetic Algorithm. Develop- ment in Design \& Decision Support Systems in Architecture and Urban Planning, 111-126. Eindhoven: Eindhoven University of Techno$\operatorname{logy}$.

Klugl, F., \& Bazzan, A. L. (2012). Agent-Based Modeling and Simulation. Association for The Advancement of Artificial Intelligence; AI Magaazine, 29-40.

Knura, M. (2019). Agent Based Simulation of Pedestrian Movement in Urban Environment. AGILE.

Kontovourkis, O. (2011). Design of Circulation Diagrams in Macro-scale Level Based on Human Movement Behavior Modelling. Automation in Construction, 22, 12-23.

Kontovourkis, O. (2011). Pedestrian Modelling as Generative Mechanism for The Design Adaptive Built Environment. eCAADe-Simulation, Visualization, Prediction and Evaluation, 850858.

Leslie, E., Coffee, N., Frank, L., Owen, N., Bauman, A., \& Hugo, G. (2007). Walkability of local communities: Using geographic information systems to objectively assess relevant environmental attributes. Health and Place, 13(1), 111122. https://doi.org/10.1016/j.healthplace.2005. 11.001

Lynch, K. (1960). The Image of The City. Cambridge, London, England: The Massachusetts Institute of Technology Press.

Penn, A., \& Turner, A. (2001). Space Syntax based Agent Simulation. 1st International Conference on Pedestrian and Evacuation Dynamics, p.7. Germany: University of Duisburg.

Ronald, N., Sterling, L., \& Kirley, M. (2007). An agent-based approach to modelling pedestrian behaviour. In Simulation. https://www.researchgate.net/publication/228931870_An_agentbased_approach_to_modelling_pedestrian_beha viour

Sharma, S. B., \& Tabak, V. (2008). Rapid Agent Based Simulation of People Flow for Design of Spaces. In Design and Decision Support Systems (DDSS) in Architecture and Urban Planning . Eindhoven, Netherlands: Eindhoven University of Technology.

Yan, W., \& Kalay, Y. E. (2006). Geometric, Cognitive, and Behavioral Modeling of Environmental (DCC). Springer. 